\title{
Perspective
}

PERSPECTIVE Actualité en histoire de l'art

Comptes rendus | 2012

\section{Sandrine Alexandre, Nora Philippe, Charlotte Ribeyrol éd., Inventer la peinture grecque antique, Lyon, ENS Éditions, 2012}

\section{Philippe Jockey}

\section{OpenEdition}

\section{Journals}

Édition électronique

URL : http://journals.openedition.org/perspective/2421

DOI : $10.4000 /$ perspective. 2421

ISSN : 2269-7721

Éditeur

Institut national d'histoire de l'art

Référence électronique

Philippe Jockey, «Sandrine Alexandre, Nora Philippe, Charlotte Ribeyrol éd., Inventer la peinture grecque antique, Lyon, ENS Éditions, $2012 »$, Perspective [En ligne], Comptes rendus, mis en ligne le 25 juillet 2013, consulté le 01 octobre 2020. URL : http://journals.openedition.org/perspective/2421 ; DOI https://doi.org/10.4000/perspective.2421

Ce document a été généré automatiquement le 1 octobre 2020. 
Sandrine Alexandre, Nora Philippe, Charlotte Ribeyrol éd., Inventer la peinture grecque antique, Lyon, ENS Éditions, 2012

Philippe Jockey

\section{RÉFÉRENCE}

Sandrine Alexandre, Nora Philippe, Charlotte Ribeyrol éd., Inventer la peinture grecque antique, Lyon, ENS Éditions, 2012. 
Sous ce titre volontairement ambivalent sont réunies, en un volume riche, à l'illustration soignée et de belle qualité, les contributions de onze spécialistes issus de disciplines variées (littérature antique, anglaise, philosophie, sciences dures, histoire et histoire de l'art) invités à se pencher sur «l'invention » de la peinture grecque au fil des âges, une peinture aujourd'hui définitivement perdue ou peu s'en faut pour nous, à quelques célèbres exceptions récentes près (décor des tombes macédoniennes, par exemple) à travers l'histoire artistique, littéraire et philosophique de ses réceptions antique,

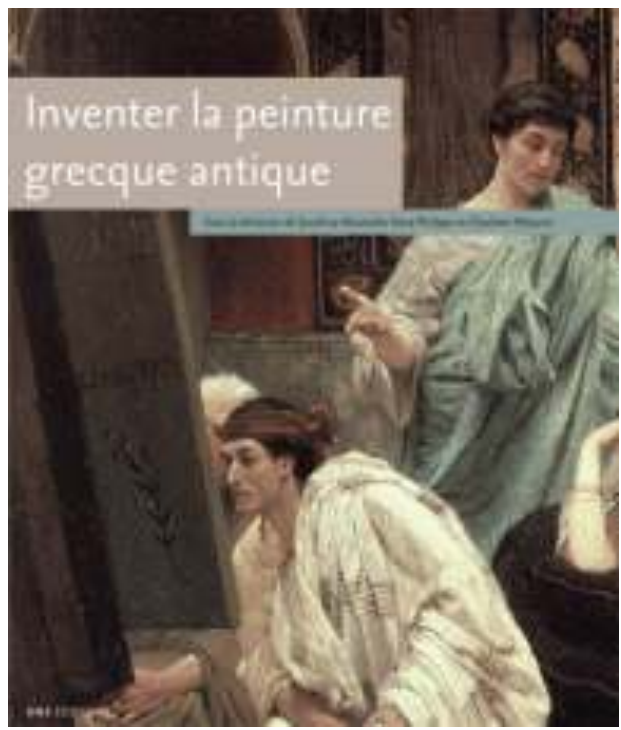
moderne et contemporaine. Un vaste corpus de textes antiques et modernes de peintres, écrivains ou historiens de l'art $\left(\mathrm{du} \mathrm{Xv}^{\mathrm{e}}\right.$ au XxI ${ }^{\mathrm{e}}$ siècle $)$ est mobilisé à l'appui de cette réflexion collective qui s'inscrit légitimement dans l'horizon intellectuel des travaux d'Agnès Rouveret (voir Perspective, 2006-1), très présents et souvent cités. La publication vient après une journée d'étude qui s'est tenue à Lyon, à l'ENS, en février 2008.

2 Le jeu sur le double sens du mot inventer, issu du latin invenire - « imaginer » mais aussi «trouver »- guide le propos des auteurs et donne à la publication son architecture matérielle et épistémologique. La présentation de données matérielles inédites ou non est délibérément circonscrite à deux articles, au demeurant passionnants, de Philippe Walter (sur les origines préhistoriques de l'art) et de Sophie Descamps-Lequime (sur la couleur des bronzes grecs.)

3 La réflexion générale est organisée en deux grands moments précédés d'un prologue (Philippe Walter) et ponctués de deux articles charnières (Sophie Descamps-Lequime ; Marie Gautheron). "L'invention antique " réunit tout d'abord trois contributions autour d'auteurs, d'anecdotes ou de textes fondateurs (Vie d'Apollonios de Tyane et La Galerie de tableaux de Philostrate, anecdote de l'invention de l'art par le potier Butadès de Sicyone, par exemple). Les "Renaissance(s) de l'invention " aux $\mathrm{XV}^{\mathrm{e}}$ et $\mathrm{XIX}^{\mathrm{e}}$ siècles sont l'objet des quatre articles suivants. Ils font une large part à la réception anglaise de la peinture antique aux $\mathrm{XVI}^{\mathrm{e}}$ et $\mathrm{XIX}^{\mathrm{e}}$ siècles par des poètes, esthètes et historiens de l'art, mais croisent aussi les regards sur la peinture ancienne de trois personnalités du monde savant ou artistique du XIX ${ }^{\mathrm{e}}$ siècle (Raoul-Rochette, Hittorf et Ingres), héritiers chacun à leur manière des antiquaires des siècles précédents et confrontés à la réapparition des couleurs perdues de la Grèce antique, à la faveur de sa vaste exploration archéologique tout au long du siècle. Il y avait là matière à une double (ré)invention de la peinture grecque. Les uns et les autres ne se sont pas privés d'en poser les termes, encore prégnants aujourd'hui, à bien des égards.

4 «L'épilogue» de cette étude aux voix multiples revient à un artiste contemporain, Pierre Antoniucci, invité à donner sa propre lecture de la peinture grecque, manière d'ekphrasis picturale bienvenue. Au texte s'ajoute un court-métrage intitulé «Visite à 
la peinture antique dans l'atelier de Pierre Antoniucci », réalisé par Philippe Nora et inséré dans l'ouvrage sous la forme d'un DVD.

5 L'ambition d'un tel ouvrage était grande. Pari tenu et l'on ne peut que se réjouir du dynamisme de la jeune équipe qui en a conçu le projet et conduit la réalisation. 